\title{
The Laetiporus polyketide synthase LpaA produces a series of antifungal polyenes
}

\author{
Paula Sophie Seibold ${ }^{1} \cdot$ Claudius Lenz $^{1} \cdot$ Markus Gressler $^{1} \cdot$ Dirk Hoffmeister $^{1}{ }^{1}$
}

Received: 30 April 2020 / Revised: 19 July 2020 / Accepted: 21 July 2020 / Published online: 21 August 2020

(c) The Author(s) 2020. This article is published with open access

\begin{abstract}
The conspicuous bright golden to orange-reddish coloration of species of the basidiomycete genus Laetiporus is a hallmark feature of their fruiting bodies, known among mushroom hunters as the "chicken of the woods". This report describes the identification of an eight-domain mono-modular highly reducing polyketide synthase as sole enzyme necessary for laetiporic acid biosynthesis. Heterologous pathway reconstitution in both Aspergillus nidulans and Aspergillus niger verified that LpaA functions as a multi-chain length polyene synthase, which produces a cocktail of laetiporic acids with a methylbranched $\mathrm{C}_{26}-\mathrm{C}_{32}$ main chain. Laetiporic acids show a marked antifungal activity on Aspergillus protoplasts. Given the multiple products of a single biosynthesis enzyme, our work underscores the diversity-oriented character of basidiomycete natural product biosynthesis.
\end{abstract}

\section{Introduction}

Non-terpenoid polyenes are a remarkable class of biologically active basidiomycete natural products. These compounds with up to ten conjugated carbon-carbon double bonds have been attributed to chemical defense: piptoporic acid (Fig. 1), a polyene from Piptoporus australiensis with seven double bonds in conjugation deters fungivorous larvae from feeding on the fruiting bodies $[1,2]$. More recently, 18-methyl-19-oxoicosaoctaenoic acid and 20-methyl-21-oxodocosanonaenoic acid (Fig. 1) of a taxonomically undescribed stereaceous basidiomycete, preliminarily referred to as BY1, were shown to inhibit pupation of larvae [3]. Biosynthetically, the respective compounds are polyketides and were instrumental in gaining first insight in polyene biogenesis in Basidiomycota as the BY1 multi-domain highly reducing polyketide synthase (HR-PKS) PPS1 was

Supplementary information The online version of this article (https:// doi.org/10.1038/s41429-020-00362-6) contains supplementary material, which is available to authorized users.

Dirk Hoffmeister

dirk.hoffmeister@leibniz-hki.de

1 Pharmaceutical Microbiology, Friedrich Schiller University, Jena, Germany functionally reconstituted in Aspergillus niger as heterologous host [4].

The intense, conspicuous orange color is the signature feature of specimens of the Laetiporus sulphureus species complex, i.e., the "chicken of the woods" fungi. These are brown-rotting bracket mushrooms that have a European and North American distribution and which are commonly found on oak, eucalypt, or willow trees. The coloration is conferred by a blend of polyenes. In previous works, Weber et al. elucidated the structure of laetiporic acid $\mathrm{A}$ and its 2 dehydro-3-deoxy derivative (Fig. 1) [5, 6], i.e., two nonterpenoid polyenes that possess a $\mathrm{C}_{26}$ main chain and share the 1-methyl-2-oxo-propylidene moiety with the above basidiomycete polyenes yet show ten conjugated double bonds. The same authors detected even longer putative polyene products, laetiporic acids $\mathrm{B}$ and $\mathrm{C}$ (with $\mathrm{C}_{28}$ and $\mathrm{C}_{30}$ main chains, respectively) by liquid chromatography and mass spectrometry.

To learn more about the structural diversity of fungal polyenes, including the as yet largely uninvestigated biosynthesis of non-aromatic polyketides in basidiomycetes, we built upon the above previous Laetiporus-related results. Herein, we describe the L. sulphureus enzyme LpaA as a multi-chain length polyene synthase. Heterologous pathway reconstitution in two independent recombinant lpaAexpressing Aspergillus species led to a polyene profile similar to that found in L. sulphureus mycelium and fruiting bodies. We demonstrate that LpaA, i.e., a single HR-PKS, 


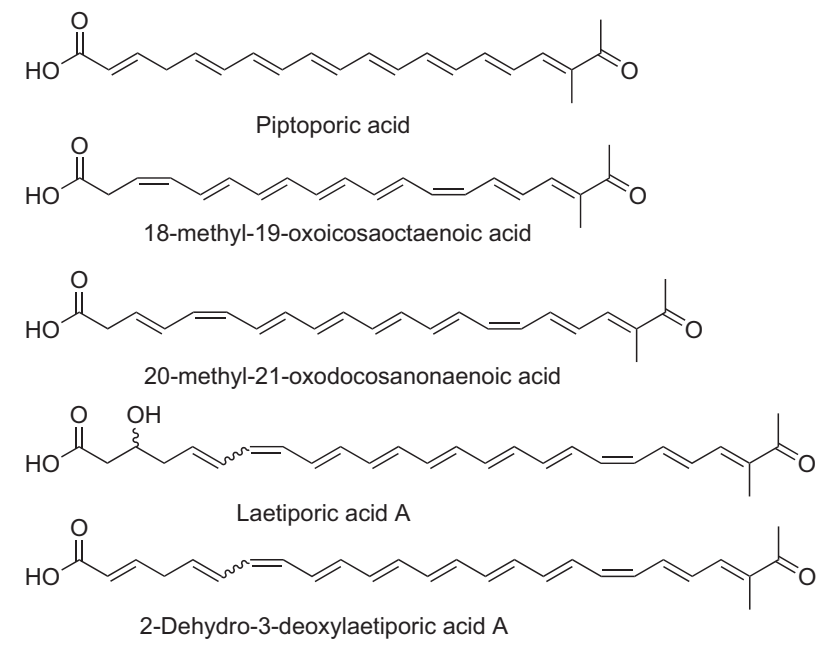

Fig. 1 Structures of basidiomycete polyenes. For laetiporic acid $\mathrm{A}$, the predominant isomer is shown (cis-configured double bond $\mathrm{C}_{7}-\mathrm{C}_{8}$ )

produces a series of compounds with $\mathrm{C}_{26}-\mathrm{C}_{32}$ main chain lengths.

\section{Materials and methods}

\section{General experimental procedures}

Semipreparative HPLC was performed on an Agilent 1260 instrument, equipped with a diode-array detector, UHPLCMS runs were done on an Agilent 1290 Infinity II chromatograph, interfaced to an Agilent 6130 single quadrupole mass detector. HR-ESI-MS spectra were recorded in positive mode on a Thermo Scientific Exactive Orbitrap instrument. UV/Vis spectra were recorded from $\lambda=$ 200-700 nm with diode array detectors connected with the respective chromatographs, chromatograms were extracted at $\lambda=450 \mathrm{~nm}$.

\section{Microbial strains and growth conditions}

Escherichia coli XL1-blue was used for routine cloning and was cultivated in LB supplemented with $50 \mu \mathrm{g} \mathrm{ml}^{-1}$ carbenicillin, if required. Laetiporus sulphureus (s.1.) JMRC SF012599 was provided by the Jena Microbial Resource Collection (JMRC) and was routinely maintained on MEP medium (per liter: malt extract $30 \mathrm{~g}$, soytone peptone $3 \mathrm{~g}$, agar $18 \mathrm{~g}$ ) for 14 days at $25^{\circ} \mathrm{C}$. To produce laetiporic acids, L. sulphureus was cultivated on 150 YPD agar plates (per liter: yeast extract $10 \mathrm{~g}$, soytone peptone $20 \mathrm{~g}$, D-glucose $20 \mathrm{~g}$, agar $18 \mathrm{~g}$ ) at $20^{\circ} \mathrm{C}$ for 14-21 days. Fruiting bodies of L. sulphureus were collected in Jena, Germany, on willow trees along the Saale river, in September 2019. Aspergillus strains used for transformation were A. niger ATNT16 A. nidulans FGSC A4.

A. niger transformants tPS01 and tPS02 were cultivated on Aspergillus minimal medium agar plates (AMM) [8] supplemented with $5 \mathrm{mM}$ L-glutamine at $30^{\circ} \mathrm{C}$ for 5-7 days. Media for ATNT16 $p y r G \times 24$ were supplemented with $10 \mathrm{mM}$ uridine. To produce laetiporic acids in recombinant $A$. niger, transformants tPS01 (vector control) and tPS02 (polyene producer) were pre-cultivated overnight in 30 Erlenmeyer flasks, each filled with $50 \mathrm{ml}$ YPD medium, at $30^{\circ} \mathrm{C}$ and $140 \mathrm{rpm}$. The main culture was a $30 \times 11$ fermentation (AMM containing $200 \mathrm{mM}$ D-glucose and $50 \mathrm{mM}$ L-glutamine), inoculated with $50 \mathrm{ml}$ pre-culture each. To induce $\operatorname{lpaA}$ expression, $30 \mathrm{mg}^{-1}$ doxycycline was added after $18 \mathrm{~h}$, and cultivation was continued for additional $48 \mathrm{~h}$. A. nidulans FGSC A4 and mutant tMG01 were maintained on AMM plates supplemented with $5 \mathrm{mM} \mathrm{L}$-glutamine at $37^{\circ} \mathrm{C}$ for 3 days. Plates for tMG01 were supplemented with $0.1 \mu \mathrm{g} \mathrm{ml}^{-1}$ pyrithiamine hydrobromide. To produce laetiporic acids in A. nidulans, the strains were cultivated in 1001 auto-inducing AMM, prepared with $200 \mathrm{mM}$ ethanol and $10 \mathrm{mM}$ D-glucose as carbon sources, at $30^{\circ} \mathrm{C}$ and $140 \mathrm{rpm}$ for $72 \mathrm{~h}$. Details on fungal strains are given in Supplementary Table S1. Aspergillus conidia were harvested with $10 \mathrm{ml}$ sterile water and the suspension was filtered by a cell strainer $(40 \mu \mathrm{m}$, EASYstrainer). Media were inoculated at a titer of $1 \times 10^{6}$ conidia per milliliter.

\section{CDNA cloning and construction of IpaA expression plasmids}

L. sulphureus mycelium was grown in liquid YPD medium at $20^{\circ} \mathrm{C}$ and $140 \mathrm{rpm}$ for 7 days, harvested, and ground under liquid nitrogen. RNA was isolated using the SV Total RNA Isolation Kit (Promega). Residual genomic DNA was digested by Baseline-ZERO DNase (Biozym). Reverse transcription was carried out with anchored oligo-dT 18 primers and RevertAid Reverse Transcriptase (ThermoFisher). The lpaA coding sequence was PCR-amplified from the first strand reaction, using the oligonucleotides oCL46 and oCL47 (Supplementary Table S2), using method A (Supplementary Table S3). The gel-purified fragment was ligated into pJET1.2 (Thermo) to yield plasmid pCL10 (Supplementary Table S4) which was sequenced (GenBank accession number MT304701) to verify accurate amplification and then served as template for subsequent PCRs. A tag-free version (8190 bp) was expressed in A. nidulans, while in $A$. niger, a gene for a hexahistidine fusion protein was used (8229 bp).

The lpaA coding sequence was PCR-amplified (method B, Supplementary Table S3) from pCL10 using oMG459 and oMG460 (Supplementary Table S2) in order 
to introduce $P a c \mathrm{I}$ sites at either end of the fragment. The $A$. niger expression vector pSMX2-URA [7], allowing for doxycycline-inducible gene expression, was modified by PCR-mediated ligation (oligonucleotides oMG457/ oMG458) to incorporate a PacI restriction site in the multiple cloning site to create vector pPS01 (Supplementary Tables S2, S4). Both the insert and pPS01 were restricted with $P a c \mathrm{I}$ and ligated to create the $\operatorname{lpaA}$ expression vector pPS03. Plasmids pPS01 (vector) and pPS03 (lpaA expression plasmid) were used to transform A. niger.

To construct an alcohol-inducible lpaA expression vector, the vector backbone of plasmid pMD03 [9] as well as the lpaA coding sequence inserted in plasmid pCL10 were amplified (method B, Supplementary Table S3) using oligonucleotides oMG468/oMG469 and oMG471/oMG472, respectively. Both fragments were ligated using the NEBuilder HiFi DNA Assembly Cloning Kit (NEB) to yield lpaA expression plasmid pMG49, which was used to transform A. nidulans. Details of plasmids are described in Supplementary Table S4.

\section{Transformation of Aspergillus species}

Protoplast transformation of A. niger and A. nidulans was carried out as previously described [7, 9]. In brief, protoplasts were obtained by incubation of mycelium with VinoflowPro $(1.1 \mathrm{~g}$ per $20 \mathrm{ml}$ volume) for $4 \mathrm{~h}$ in YAT buffer $(0.6 \mathrm{M} \mathrm{KCl}, 50 \mathrm{mM}$ maleic acid, $\mathrm{pH} 5.5)$ and $10 \mu \mathrm{g}$ of plasmid DNA (pPS01 and pPS03 for A. niger, pMG49 for $A$. nidulans) were used for polyethylene glycol-mediated transformation. A. niger transformants (tPS01 and tPS02) were selected by uracil prototrophy, while $A$. nidulans transformants (tMG01) were selected by pyrithiamine resistance in presence of $0.1 \mu \mathrm{g} \mathrm{ml}^{-1}$ pyrithiamine. Integration of the IpaA gene was confirmed by PCR (Supplementary Table S3, methods C and D).

\section{UHPLC analysis of laetiporic acids}

Methanolic crude extracts of mycelia from Aspergilli and Laetiporus mycelia and carpophores were centrifuged, filtered, and were subjected to UHPLC measurements. Method B (Supplementary Table S5) was used for initial screening of extracts of positive transformants or selection of fractions containing laetiporic acids during the purification procedure (see below). Method B was also applied for polyene quantification in growth inhibition assays.

\section{Purification of laetiporic acids}

One-hundred and fifty Laetiporus agar plates were diced, lyophilized, and extracted with acetone $(3 \times 51)$. Aspergillus mycelia were collected, washed with water, and lyophilized.
Mycelia were ground to a fine powder and extracted six times with methanol and subsequently twice with acetone (50 $\mathrm{ml}$ per $1 \mathrm{~g}$ dry biomass and extraction).

Aspergillus and Laetiporus extracts were filtered through cellulose round filters and evaporated to dryness. The dry residue was dissolved in 21 water and repeatedly extracted with a total of 121 ethyl acetate. The organic phase was evaporated. The residue was dissolved in $400 \mathrm{ml}$ methanol, and $40 \mathrm{ml}$ aliquots were subjected to size exclusion chromatography on Sephadex LH-20 $(60 \times 4 \mathrm{~cm})$ with methanol as eluent. Three fractions (FI-III) were obtained, containing laetiporic acid (LA)-A, LA-B in F-I, LA-C in F-II, and LA-D and traces of other derivatives in F-III. All fractions were subjected to reversed phase semi-preparative HPLC, using methods C (F-I and F-II) and D (F-III) (Supplementary Table S5). Isolated compounds were lyophilized and dissolved in methanol. Final work up was accomplished under slightly basic conditions (method E for LA-A and LA-B, method F for LA-D, Supplementary Table S5).

To test for photoisomerization, $100 \mu \mathrm{g} \mathrm{ml}^{-1}$ of Aspergillus-produced laetiporic acids $\mathrm{A}_{1}, \mathrm{~B}_{1}$, or $\mathrm{B}_{2}$, respectively, or laetiporic acid $\mathrm{A}_{1}$ from L. sulphureus were continuously exposed to light for $24 \mathrm{~h}$ (or in the dark for control). After exposure, the solutions were chromatographically analyzed by UHPLC-MS (method A, Supplementary Table S5).

\section{Growth inhibition assays}

Cultivations were carried out in triplicate at $30{ }^{\circ} \mathrm{C}$ and $140 \mathrm{rpm}$ with a conidial titer of $1 \times 10^{6}$ per $\mathrm{ml}$ in $30 \mathrm{ml}$ medium. A. niger tPS01 and tPS02 were cultivated in AMM $(+200$ $\mathrm{mM}$ D-glucose and $50 \mathrm{mM}$ L-glutamine) for $42 \mathrm{~h}$. Doxycycline hydrochloride $\left(0,7.5,15,30,60\right.$, or $\left.120 \mu \mathrm{g} \mathrm{ml}^{-1}\right)$ was added immediately after inoculation. A. nidulans strains were cultivated in AMM without glucose, but with $200 \mathrm{mM}$ ethanol as sole carbon source (inducing condition) for $72 \mathrm{~h}$. For delayed gene expression, D-glucose $(0,2.5,5,10$, or $50 \mathrm{mM}$ ) was added prior to inoculation. AMM with $200 \mathrm{mM}$ D-glucose (repressing condition) served as negative control. After cultivation, the mycelium was lyophilized, weighted, ground to a fine powder, and extracted with $1 \mathrm{ml}$ methanol for $5 \mathrm{~min}$ in an ultrasonic bath. After centrifugation $(10 \mathrm{~min}, 13,000 \mathrm{~g})$, an aliquot of $5 \mu \mathrm{l}$ was subjected to HPLC analysis (method A, Supplementary Table S5) and polyene signals were manually integrated $(\lambda=450 \mathrm{~nm}$, $t_{\mathrm{R}}=4-8 \mathrm{~min}$ ). Polyenes were quantified against a calibration curve with respective SEC-purified polyenes as authentic reference standards.

\section{Protoplast toxicity assays}

To obtain polyene-containing and control extracts, $A$. nidulans was cultivated in AMM $(+10 \mathrm{mM}$ D-glucose and 


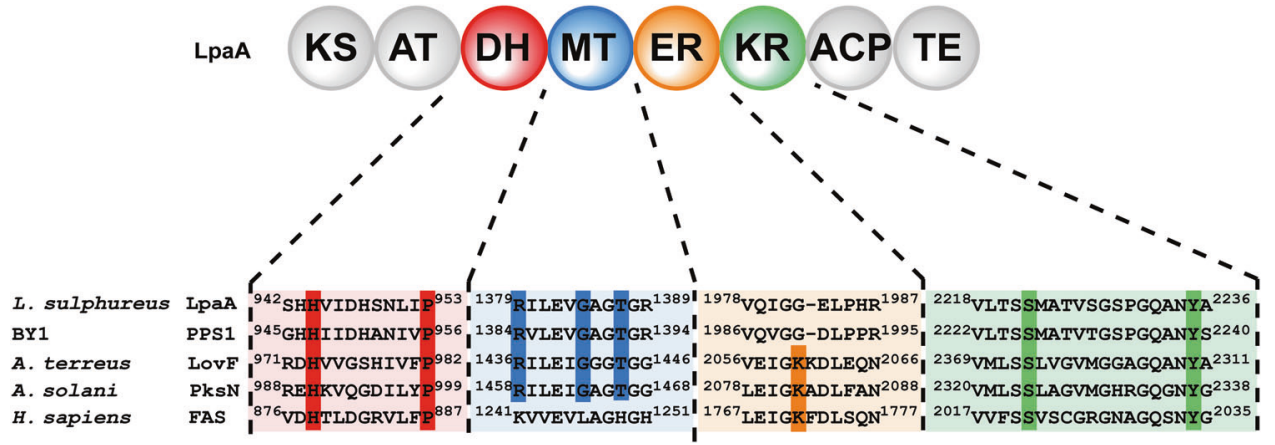

Fig. 2 Domain setup of LpaA. Domain abbreviations: $\beta$-keto synthase (KS), acyltransferase (AT), dehydratase (DH), methyltransferase (MT), enoyl reductase (ER), $\beta$-keto reductase (KR), acyl carrier protein (ACP), thioesterase (TE). Below: amino acid sequence alignments of the active site of the respective domains. Conserved residues are highlighted with vertical color-coded bars. BY1 mushroom polyene synthase PPS1 (NCBI accession \#: KX819293.1); A. terreus LovF: Aspergillus terreus lovastatin diketide synthase (Q9Y7D5.1); A. solani PksN: Alternaria solani alternapyrone synthase (BAD83684.1); H. sapiens FAS: human fatty acid synthase (NP_004095.4). A MT domain is not present in the human FAS. The ER domain is inactive in LpaA and PPS1. A TE domain is not present in LovF and PksN

$200 \mathrm{mM}$ ethanol) at $30^{\circ} \mathrm{C}$ and $140 \mathrm{rpm}$ for $72 \mathrm{~h}$. Lyophilized mycelium $(5 \mathrm{~g})$ was ground to a powder and extracted five times with $200 \mathrm{ml}$ methanol. Extracts were purified via size exclusion chromatography with Sephadex LH-20 as described above. Fractions were analyzed with UHPLCMS, and fractions containing laetiporic acids were pooled for tMG01 and added in concentrations from $31 \mu \mathrm{g} \mathrm{ml}^{-1}$ to $4 \mathrm{mg} \mathrm{ml}^{-1}$. As negative control, appropriate SEC fractions of $A$. nidulans wild type were pooled accordingly. The eluates were dried under reduced pressure and residues were suspended in sterile YAT buffer.

To produce protoplasts, A. nidulans mycelium was filtered, washed with sterile YAT buffer, and incubated in lysis solution (1.3 g VinoTaste Pro (Novozymes), $0.1 \mathrm{~g}$ lysing enzymes from Trichoderma harzianum (Sigma), $0.1 \mathrm{~g}$ Yatalase (Takara), in $20 \mathrm{ml}$ YAT buffer) at $30^{\circ} \mathrm{C}$ and $70 \mathrm{rpm}$ for $3 \mathrm{~h}$. Protoplasts were filtered through sterile Miracloth, washed with YAT buffer, counted, and diluted to a final titer of $2 \times 10^{4}$ protoplasts per ml. $100 \mu \mathrm{l}\left(2 \times 10^{3}\right.$ cells) of the cell suspension were gently mixed with the same volume of extracts (A. nidulans FGSCA4 or tMG01), and protoplasts were incubated on ice for $3 \mathrm{~h}$. Suspensions were carefully plated on osmotic AMM plates (with $1.2 \mathrm{M}$ sorbitol, $100 \mathrm{mM}$ D-glucose, $20 \mathrm{mM}$ L-glutamine, $\mathrm{pH}$ 6.5) and incubated at room temperature for $96 \mathrm{~h}$. Colony forming units from four independent experiments were counted.

\section{Results}

\section{Identification of HR-PKS genes in L. sulphureus}

The chemical structures of the laetiporic acids from L. sulphureus and the polyenes isolated from the BY1 mushroom differ in their chain length, yet share a 1-methyl2-oxo-1-propylidene moiety and a shifted conjugated double bond system, i.e., the double bonds are positioned within the formal acetate units. We therefore used the sequence of PPS1, the only known basidiomycete polyene synthase, as query to browse the published genome of L. sulphureus [10]. We identified two near-identical HRPKS genes, now collectively referred to as $\operatorname{lpaA}$, that both encode proteins of 2729 amino acids (95\% identical and $97 \%$ similar amino acids) with a corresponding molecular mass of $296 \mathrm{kDa}$. The predicted domain architecture ketosynthase-acyltransferase-dehydratase-methyltransferase-enoylreductase-ketoreductase-acyl carrier proteinthioesterase (KS-AT-DH-MT-ER ${ }^{0}-\mathrm{KR}-\mathrm{ACP}-\mathrm{TE}$, Fig. 2) is consistent with the enzymatic requirements to biosynthesize a methyl branched polyene. The protein LpaA shared $68 \%$ identity ( $81 \%$ similarity) to PPS 1 . Analyses of amino acid sequences identified conserved canonical active sites in all domains, except the ER domain. Consistent with the not fully reduced laetiporic acids, we assumed that the ER domain in LpaA was most likely not functional. Usually, a lysine residue serves as a proton donor during reduction of the enoyl [11]. This role was evident in mammalian fatty acid synthases $\left(\mathrm{K}^{1771}\right)$ [12], or fully reducing PKSs, such as LovF from Aspergillus terreus $\left(\mathrm{K}^{2060}\right)$ [13] and Alternaria solani PKSN ( $\left.\mathrm{K}^{2082}\right)$ [14]. However, in LpaA, and PPS1 alike, this lysine residue is replaced by glycine $\left(\mathrm{G}^{1982}\right.$ and $\mathrm{G}^{1990}$ ), respectively, indicating a structural rather than a catalytic function of the ER (Fig. 2).

\section{Construction of recombinant, IpaA-expressing Aspergillus niger}

L. sulphureus produces laetiporic acid A in fruiting bodies as well as in mycelia, as described [5] and confirmed in our study by UHPLC-MS and HR-MS (Fig. 3). To investigate the function of $\operatorname{lpaA}$, the full-length gene was amplified 

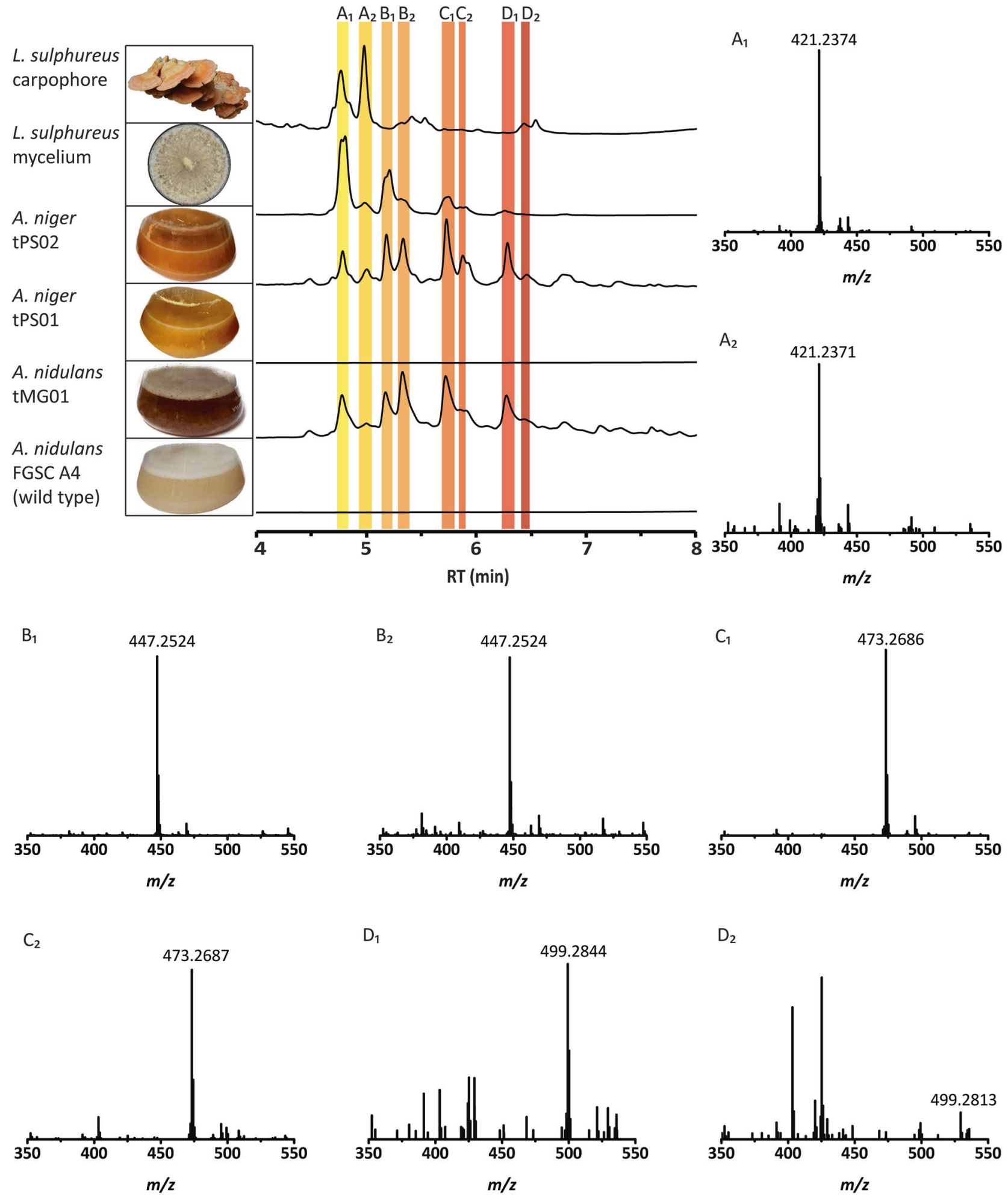
Fig. 3 UHPLC profiles of metabolic extracts from cultures of $L$. sulphureus, lpaA-expressing Aspergillus strains and their respective control strains. Representative pictures of the fruiting bodies or cultures are presented (left). UHPLC profiles (top to bottom) of methanolic extracts from $L$. sulphureus carpophores, vegetative mycelium of L. sulphureus, A. niger tPS02 (lpaA-expressing), A. niger tPS01 (vector control), A. nidulans tMG01 (lpaA-expressing) and A. nidulans FGSC4 wildtype strain. Peaks for laetiporic acids $\mathrm{A}_{1}-\mathrm{D}_{2}$ are indicated by colored bars. Chromatograms were extracted at $\lambda=450 \mathrm{~nm}$. Minor UV-absorbing compounds surrounding laetiporic acids $A_{1}-D_{2}$ are present that have not been identified, but were absent in the controls. Respective high-resolution mass spectra are given for laetiporic acids $\mathrm{A}_{1}-\mathrm{D}_{2}$ purified from $A$. niger. Polyene peak intensities of mass spectra range between $6 \times 10^{5}\left(\mathrm{LA}_{2}\right)$ and $1.8 \times 10^{7}\left(\mathrm{LA}-\mathrm{B}_{1}\right)$. Please refer to Table 1 for $\mathrm{MS}^{2}$ data. LA- $\mathrm{D}_{2}$ was produced in insufficient quantities for further analysis

presence and absence of doxycycline, but immediate induction led to poor growth of tPS02, while it did not impact growth of tPS01. To produce sufficient biomass for further chromatographic analysis, the cultures were induced with doxycycline $\left(30 \mathrm{mg} \mathrm{l}^{-1}\right) 18 \mathrm{~h}$ post inoculation. The cultivation was continued for another $48 \mathrm{~h}$ during which mycelium of tPS02 turned orange (Fig. 3), while both the culture supernatant and the control strain tPS01 did not change their color.

\section{Identification of laetiporic acids from IpaA- expressing Aspergillus strains}

Mycelia of the induced transformants tPS01 and tPS02 were extracted with methanol. A subsequent UHPLC-MS analysis revealed various novel signals in tPS02 at $\lambda=450 \mathrm{~nm}$, compared to the control tPS01. UV/Vis spectra of the new peaks showed absorption maxima between $\lambda=430-480 \mathrm{~nm}$ (Supplementary Fig. S2) and were reminiscent of the spectra of BY1 polyenes 18-methyl-19-oxoicosaoctaenoic acid and 20-methyl-21-oxodocosanonaenoic acid [4]. We therefore hypothesized the signals may reflect the presence of polyenes due to activity of LpaA in vivo. Curiously, a series of masses was found which followed a regular pattern in increments of $m / z+26$, i.e., $\mathrm{C}_{2} \mathrm{H}_{2}$ (Table 1). The eight most abundant peaks (Fig. 3) were purified by size exclusion and semipreparative liquid chromatography and were finally subjected to HR-MS/MS detecting over a range between $\mathrm{m} / \mathrm{z} 200$ and 1400. Three detected signals are compatible with the masses of laetiporic acids $\mathrm{A}_{1}\left(\mathrm{~m} / z 421[\mathrm{M}+\mathrm{H}]^{+}\right)$, $\mathrm{B}_{1}\left(\mathrm{~m} / z 447[\mathrm{M}+\mathrm{H}]^{+}\right)$and $\mathrm{C}_{1}\left(\mathrm{~m} / z 473[\mathrm{M}+\mathrm{H}]^{+}\right)$as previously described [5]. Furthermore, we found a compound with $m / z, 499[\mathrm{M}+\mathrm{H}]^{+}$which we preliminarily refer to as laetiporic acid $\mathrm{D}_{1}$. The masses point to main chain lengths of $\mathrm{C}_{26}-\mathrm{C}_{32}$. Surprisingly, this set of masses appeared duplicated (laetiporic acids $\mathrm{A}_{2},\left(\mathrm{~m} / \mathrm{z} 421[\mathrm{M}+\mathrm{H}]^{+}\right), \mathrm{B}_{2}(\mathrm{~m} / \mathrm{z}$ $\left.447[\mathrm{M}+\mathrm{H}]^{+}\right), \mathrm{C}_{2}\left(\mathrm{~m} / \mathrm{z} 473[\mathrm{M}+\mathrm{H}]^{+}\right)$and $\mathrm{D}_{2}(\mathrm{~m} / \mathrm{z} 499[\mathrm{M}$ $+\mathrm{H}^{+}$) which may reflect a cis/trans-isomerization of the polyene backbone. A 7-cis isomer corresponding to the 7trans laetiporic acid A has previously been isolated from L. sulphureus [5, 6]. Additional confirmation that laetiporic acids had been produced in the transgenic Aspergilli came from comparative LC-MS ${ }^{2}$ analysis of laetiporic acid $\mathrm{A}_{1}$ with a standard isolated from mycelium of the original producer L. sulphureus (Figures S3 and S4) which yielded virtually identical signal patterns. Laetiporic acids were described as stable compounds [5]. To confirm these prior results, we exposed laetiporic acids $A_{1}$, (isolated both from Aspergillus niger tPSO2 and L. sulphureus), $\mathrm{B}_{1}$, and $\mathrm{B}_{2}$, respectively, to light for $24 \mathrm{~h}$, or kept them in the dark for control. Chromatographic analysis did not indicate new signals, which supports the notion of laetiporic acids as stable compounds (Supplementary Fig. S5). In return, this finding suggests that the polyene diversity is an inherent feature of Laetiporus polyketide biosynthesis.

The notorious very poor solubility of laetiporic acids $\left(<1 \mathrm{mg} \mathrm{ml}^{-1}\right)$ in organic solvents [5] such as methanol, chloroform, dichloromethane, cyclohexane, butanol, or acetone, combined with the structural similarity of the various compounds prevented recording of unambiguous NMR spectra to confirm structures and, in particular, double bond positions and configurations. For further characterization, we therefore resorted to $\mathrm{MS}^{2}$ experiments (Table 1, Supplementary Fig. S3) for seven out of eight metabolites. As expected for $\beta$-hydroxy acids, $\mathrm{MS}^{2}$ spectra revealed a consistent prevalence for dehydration $\left(m / z[\mathrm{M}-18+\mathrm{H}]^{+}\right)$and decarboxylation $\left(\mathrm{m} / \mathrm{z}[\mathrm{M}-44+\mathrm{H}]^{+}\right)$during fragmentation of all identified laetiporic acids. Moreover, the elimination of aromatic rings such as benzene $\left(m / z \quad 79[\mathrm{M}+\mathrm{H}]^{+}\right)$by electrocyclic butyl ring contraction provided a defined MS fingerprint for the linear polyene structure of laetiporic acids resulting in $\mathrm{MS}^{2}$ fragments of $m / z[\mathrm{M}-78+\mathrm{H}]^{+}$. This is in agreement with electrocyclic aromatic elimination of toluene and xylene observed in ESI-based $\mathrm{MS}^{2}$ fragmentation of polyene-like carotenoids $[15,16]$.

Beyond these eight laetiporic acids, we detected traces of another set of very minor signals that overlapped with the major peaks. The molecular masses of the latter indicated dehydrated analogs $\left.(\mathrm{m} / \mathrm{z}, \mathrm{M}-18+\mathrm{H}]^{+}\right)$of laetiporic acids A-D to give presumably 2-dehydro-3-deoxylaetiporic acids A-D $\left(m / z, 403,429,455\right.$, and $481[\mathrm{M}+\mathrm{H}]^{+}$, respectively). These compounds were produced in amounts that were insufficient for further analysis. Still, a very similar phenomenon was recognized previously when 2-dehydro-3deoxylaetiporic acid A (Fig. 1) was identified as a side product from L. sulphureus [6].

The above findings are remarkable in that one single PKS makes polyenes of (i) different chain length $\left(\mathrm{C}_{26}-\mathrm{C}_{32}\right)$ and (ii) different degree of hydroxylation. Although precedence exists for variable chain lengths of HR-PKS PPS1 $\left(\mathrm{C}_{20}-\mathrm{C}_{22}\right)$ of the basidiomycete BY1 [4] and T-toxin 
Table $1 \mathrm{MS}$ and $\mathrm{MS}^{2}$ data of laetiporic acid pairs $\mathrm{A}_{1} / \mathrm{A}_{2}-\mathrm{D}_{1} / \mathrm{D}_{2}$

\begin{tabular}{|c|c|c|c|c|c|c|c|}
\hline \multirow[t]{2}{*}{ Compound } & \multirow[t]{2}{*}{$t_{\mathrm{R}}(\min )$} & \multirow[t]{2}{*}{ Formula } & \multirow[t]{2}{*}{ Neutral mass $[\mathrm{M}]$} & \multirow[t]{2}{*}{ Found parental ion $[\mathrm{M}+\mathrm{H}]^{+}$} & \multicolumn{3}{|c|}{$\mathrm{MS}^{2}$ specific ions } \\
\hline & & & & & Ion mass & Formula & Origin \\
\hline \multirow[t]{11}{*}{$\mathrm{LA}-\mathrm{A}_{1} / \mathrm{A}_{2}$} & \multirow[t]{11}{*}{$4.7 / 4.9$} & \multirow[t]{11}{*}{$\mathrm{C}_{27} \mathrm{H}_{32} \mathrm{O}_{4}$} & \multirow[t]{11}{*}{420.2301} & \multirow[t]{11}{*}{$421.2374 / 421.2371$} & 403.227 & $\mathrm{C}_{27} \mathrm{H}_{31} \mathrm{O}_{3}$ & {$\left[\mathrm{M}-\mathrm{H}_{2} \mathrm{O}+\mathrm{H}\right]^{+}$} \\
\hline & & & & & 385.216 & $\mathrm{C}_{27} \mathrm{H}_{29} \mathrm{O}_{2}$ & {$\left[\mathrm{M}-2 \mathrm{H}_{2} \mathrm{O}+\mathrm{H}\right]^{+}$} \\
\hline & & & & & 359.236 & $\mathrm{C}_{26} \mathrm{H}_{31} \mathrm{O}$ & {$\left[\mathrm{M}-\mathrm{H}_{2} \mathrm{O}-\mathrm{CO}_{2}+\mathrm{H}\right]^{+}$} \\
\hline & & & & & 343.190 & $\mathrm{C}_{21} \mathrm{H}_{27} \mathrm{O}_{4}$ & {$\left[\mathrm{M}-\mathrm{C}_{6} \mathrm{H}_{6}+\mathrm{H}\right]^{+}$} \\
\hline & & & & & 245.132 & $\mathrm{C}_{19} \mathrm{H}_{17}$ & {$\left[\mathrm{M}-\mathrm{C}_{8} \mathrm{H}_{8}-\mathrm{H}_{8} \mathrm{O}_{4}+\mathrm{H}\right]^{+}$} \\
\hline & & & & & 219.117 & $\mathrm{C}_{17} \mathrm{H}_{15}$ & {$\left[\mathrm{M}-\mathrm{C}_{10} \mathrm{H}_{10}-\mathrm{H}_{8} \mathrm{O}_{4}+\mathrm{H}\right]^{+}$} \\
\hline & & & & & 193.101 & $\mathrm{C}_{15} \mathrm{H}_{13}$ & {$\left[\mathrm{M}-\mathrm{C}_{12} \mathrm{H}_{12}-\mathrm{H}_{8} \mathrm{O}_{4}+\mathrm{H}\right]^{+}$} \\
\hline & & & & & 131.086 & $\mathrm{C}_{10} \mathrm{H}_{11}$ & {$\left[\mathrm{C}_{10} \mathrm{H}_{10}+\mathrm{H}\right]^{+}$} \\
\hline & & & & & 109.065 & $\mathrm{C}_{7} \mathrm{H}_{10} \mathrm{O}$ & {$\left[\mathrm{C}_{7} \mathrm{H}_{9} \mathrm{O}+\mathrm{H}\right]^{+}$} \\
\hline & & & & & 105.070 & $\mathrm{C}_{8} \mathrm{H}_{9}$ & {$\left[\mathrm{C}_{8} \mathrm{H}_{8}+\mathrm{H}\right]^{+}$} \\
\hline & & & & & 79.054 & $\mathrm{C}_{6} \mathrm{H}_{7}$ & {$\left[\mathrm{C}_{6} \mathrm{H}_{6}+\mathrm{H}\right]^{+}$} \\
\hline \multirow[t]{13}{*}{$\mathrm{LA}-\mathrm{B}_{1} / \mathrm{B}_{2}$} & \multirow[t]{13}{*}{$5.1 / 5.3$} & \multirow[t]{13}{*}{$\mathrm{C}_{29} \mathrm{H}_{34} \mathrm{O}_{4}$} & \multirow[t]{13}{*}{446.2457} & \multirow[t]{13}{*}{$447.2524 / 447.2524$} & 429.242 & $\mathrm{C}_{29} \mathrm{H}_{33} \mathrm{O}_{3}$ & {$\left[\mathrm{M}-\mathrm{H}_{2} \mathrm{O}+\mathrm{H}\right]^{+}$} \\
\hline & & & & & 411.231 & $\mathrm{C}_{29} \mathrm{H}_{31} \mathrm{O}_{2}$ & {$\left[\mathrm{M}-2 \mathrm{H}_{2} \mathrm{O}+\mathrm{H}\right]^{+}$} \\
\hline & & & & & 369.204 & $\mathrm{C}_{23} \mathrm{H}_{29} \mathrm{O}_{4}$ & {$\left[\mathrm{M}-\mathrm{C}_{6} \mathrm{H}_{6}+\mathrm{H}\right]^{+}$} \\
\hline & & & & & 351.195 & $\mathrm{C}_{23} \mathrm{H}_{27} \mathrm{O}_{3}$ & {$\left[\mathrm{M}-\mathrm{C}_{6} \mathrm{H}_{6}-\mathrm{H}_{2} \mathrm{O}+\mathrm{H}\right]^{+}$} \\
\hline & & & & & 312.172 & $\mathrm{C}_{20} \mathrm{H}_{24} \mathrm{O}_{3}$ & {$\left[\mathrm{M}-\mathrm{C}_{9} \mathrm{H}_{9}-\mathrm{H}_{2} \mathrm{O}+\mathrm{H}\right]^{+}$} \\
\hline & & & & & 271.148 & $\mathrm{C}_{21} \mathrm{H}_{19}$ & {$\left[\mathrm{M}-\mathrm{C}_{8} \mathrm{H}_{8}-\mathrm{H}_{8} \mathrm{O}_{4}+\mathrm{H}\right]^{+}$} \\
\hline & & & & & 245.132 & $\mathrm{C}_{19} \mathrm{H}_{17}$ & {$\left[\mathrm{M}-\mathrm{C}_{10} \mathrm{H}_{10}-\mathrm{H}_{8} \mathrm{O}_{4}+\mathrm{H}\right]^{+}$} \\
\hline & & & & & 219.117 & $\mathrm{C}_{17} \mathrm{H}_{15}$ & {$\left[\mathrm{M}-\mathrm{C}_{12} \mathrm{H}_{12}-\mathrm{H}_{8} \mathrm{O}_{4}+\mathrm{H}\right]^{+}$} \\
\hline & & & & & 193.101 & $\mathrm{C}_{15} \mathrm{H}_{13}$ & {$\left[\mathrm{M}-\mathrm{C}_{14} \mathrm{H}_{14}-\mathrm{H}_{8} \mathrm{O}_{4}+\mathrm{H}\right]^{+}$} \\
\hline & & & & & 131.086 & $\mathrm{C}_{10} \mathrm{H}_{11}$ & {$\left[\mathrm{C}_{10} \mathrm{H}_{10}+\mathrm{H}\right]^{+}$} \\
\hline & & & & & 109.065 & $\mathrm{C}_{7} \mathrm{H}_{10} \mathrm{O}$ & {$\left[\mathrm{C}_{7} \mathrm{H}_{9} \mathrm{O}+\mathrm{H}\right]^{+}$} \\
\hline & & & & & 105.070 & $\mathrm{C}_{8} \mathrm{H}_{9}$ & {$\left[\mathrm{C}_{8} \mathrm{H}_{8}+\mathrm{H}\right]^{+}$} \\
\hline & & & & & 79.054 & $\mathrm{C}_{6} \mathrm{H}_{7}$ & {$\left[\mathrm{C}_{6} \mathrm{H}_{6}+\mathrm{H}\right]^{+}$} \\
\hline \multirow[t]{10}{*}{ LA- $\mathrm{C}_{1} / \mathrm{C}_{2}$} & \multirow[t]{10}{*}{$5.7 / 5.9$} & \multirow[t]{10}{*}{$\mathrm{C}_{31} \mathrm{H}_{36} \mathrm{O}_{4}$} & \multirow[t]{10}{*}{472.2614} & \multirow[t]{10}{*}{$473.2686 / 473.2687$} & 455.258 & $\mathrm{C}_{31} \mathrm{H}_{35} \mathrm{O}_{3}$ & {$\left[\mathrm{M}-\mathrm{H}_{2} \mathrm{O}+\mathrm{H}\right]^{+}$} \\
\hline & & & & & 395.219 & $\mathrm{C}_{25} \mathrm{H}_{31} \mathrm{O}_{4}$ & {$\left[\mathrm{M}-\mathrm{C}_{6} \mathrm{H}_{6}+\mathrm{H}\right]^{+}$} \\
\hline & & & & & 338.188 & $\mathrm{C}_{22} \mathrm{H}_{26} \mathrm{O}_{3}$ & {$\left[\mathrm{M}-\mathrm{C}_{9} \mathrm{H}_{9}-\mathrm{H}_{2} \mathrm{O}+\mathrm{H}\right]^{+}$} \\
\hline & & & & & 245.132 & $\mathrm{C}_{19} \mathrm{H}_{17}$ & {$\left[\mathrm{M}-\mathrm{C}_{12} \mathrm{H}_{12}-\mathrm{H}_{8} \mathrm{O}_{4}+\mathrm{H}\right]^{+}$} \\
\hline & & & & & 219.117 & $\mathrm{C}_{17} \mathrm{H}_{15}$ & {$\left[\mathrm{M}-\mathrm{C}_{14} \mathrm{H}_{14}-\mathrm{H}_{8} \mathrm{O}_{4}+\mathrm{H}\right]^{+}$} \\
\hline & & & & & 193.101 & $\mathrm{C}_{15} \mathrm{H}_{13}$ & {$\left[\mathrm{M}-\mathrm{C}_{16} \mathrm{H}_{16}-\mathrm{H}_{8} \mathrm{O}_{4}+\mathrm{H}\right]^{+}$} \\
\hline & & & & & 131.086 & $\mathrm{C}_{10} \mathrm{H}_{11}$ & {$\left[\mathrm{C}_{10} \mathrm{H}_{10}+\mathrm{H}\right]^{+}$} \\
\hline & & & & & 109.065 & $\mathrm{C}_{7} \mathrm{H}_{10} \mathrm{O}$ & {$\left[\mathrm{C}_{7} \mathrm{H}_{9} \mathrm{O}+\mathrm{H}\right]^{+}$} \\
\hline & & & & & 105.070 & $\mathrm{C}_{8} \mathrm{H}_{9}$ & {$\left[\mathrm{C}_{8} \mathrm{H}_{8}+\mathrm{H}\right]^{+}$} \\
\hline & & & & & 79.054 & $\mathrm{C}_{6} \mathrm{H}_{7}$ & {$\left[\mathrm{C}_{6} \mathrm{H}_{6}+\mathrm{H}\right]^{+}$} \\
\hline \multirow[t]{10}{*}{ LA-D ${ }_{1}$} & 6.2 & $\mathrm{C}_{33} \mathrm{H}_{38} \mathrm{O}_{4}$ & 498.2770 & 499.2844 & 481.2742 & $\mathrm{C}_{33} \mathrm{H}_{37} \mathrm{O}_{3}$ & {$\left[\mathrm{M}-\mathrm{H}_{2} \mathrm{O}+\mathrm{H}\right]^{+}$} \\
\hline & & & & & 421.2373 & $\mathrm{C}_{27} \mathrm{H}_{33} \mathrm{O}_{4}$ & {$\left[\mathrm{M}-\mathrm{C}_{6} \mathrm{H}_{6}+\mathrm{H}\right]^{+}$} \\
\hline & & & & & 364.203 & $\mathrm{C}_{24} \mathrm{H}_{28} \mathrm{O}_{3}$ & {$\left[\mathrm{M}-\mathrm{C}_{9} \mathrm{H}_{9}-\mathrm{H}_{2} \mathrm{O}+\mathrm{H}\right]^{+}$} \\
\hline & & & & & 297.163 & $\mathrm{C}_{23} \mathrm{H}_{21}$ & {$\left[\mathrm{M}-\mathrm{C}_{10} \mathrm{H}_{10}-\mathrm{H}_{8} \mathrm{O}_{4}+\mathrm{H}\right]^{+}$} \\
\hline & & & & & 219.117 & $\mathrm{C}_{17} \mathrm{H}_{15}$ & {$\left[\mathrm{M}-\mathrm{C}_{16} \mathrm{H}_{16}-\mathrm{H}_{8} \mathrm{O}_{4}+\mathrm{H}\right]^{+}$} \\
\hline & & & & & 193.101 & $\mathrm{C}_{15} \mathrm{H}_{13}$ & {$\left[\mathrm{M}-\mathrm{C}_{18} \mathrm{H}_{18}-\mathrm{H}_{8} \mathrm{O}_{4}+\mathrm{H}\right]^{+}$} \\
\hline & & & & & 131.086 & $\mathrm{C}_{10} \mathrm{H}_{11}$ & {$\left[\mathrm{C}_{10} \mathrm{H}_{10}+\mathrm{H}\right]^{+}$} \\
\hline & & & & & 109.065 & $\mathrm{C}_{7} \mathrm{H}_{10} \mathrm{O}$ & {$\left[\mathrm{C}_{7} \mathrm{H}_{9} \mathrm{O}+\mathrm{H}\right]^{+}$} \\
\hline & & & & & 105.070 & $\mathrm{C}_{8} \mathrm{H}_{9}$ & {$\left[\mathrm{C}_{8} \mathrm{H}_{8}+\mathrm{H}\right]^{+}$} \\
\hline & & & & & 79.054 & $\mathrm{C}_{6} \mathrm{H}_{7}$ & {$\left[\mathrm{C}_{6} \mathrm{H}_{6}+\mathrm{H}\right]^{+}$} \\
\hline LA-D ${ }_{2}$ & 6.4 & $\mathrm{C}_{33} \mathrm{H}_{38} \mathrm{O}_{4}$ & 498.2770 & 499.2832 & not determ & ned. & \\
\hline
\end{tabular}


$\left(\mathrm{C}_{35}-\mathrm{C}_{45}\right)$ the high virulence determinant of the ascomycetous maize pathogen Cochliobolus heterostrophus [17], the wide spectrum of metabolites produced by LpaA in A. niger might be a host-specific effect. Laetiporic acids $A_{1}$ and $A_{2}$ are the major metabolites isolated from the fruiting body or the mycelium of L. sulphureus [6]. In contrast, heterologous production predominantly resulted in laetiporic acids $\mathrm{B}$ and C (Fig. 3). Therefore, A. nidulans FGSC A4 was tested as alternative host and transformed with plasmid pMG49 in which the lpaA gene is controlled by the ethanol-inducible, but glucose-repressible alcohol-dehydrogenase promoter (PalcA, Supplementary Tables S1, S4 and Supplementary Fig. S1) [18]. The resulting transformant tMG01 and the wild type show comparable growth in presence of D-glucose. However, growth was impeded when ethanol was used as sole carbon source indicating similar toxic effects of laetiporic acids as observed for A. niger. When supplemented with $10 \mathrm{mM}$ D-glucose, the mutant showed a strongly retarded growth and its mycelium turned orange to intense red (Fig. 3). Mycelial extracts from tMG01 were analyzed by UHPLC-MS and revealed a similar chromatographic profile as observed for the lpaA-expressing A. niger mutant tPS02. In contrast, no signals at $\lambda=450 \mathrm{~nm}$ were detectable in the parental strain. In summary, these results confirmed laetiporic acids $A_{1}-D_{2}$ as products of LpaA and point to an antifungal activity of laetiporic acids when produced in situ.

\section{Antifungal activity of laetiporic acids}

To follow up on the impeded growth of polyene-producing Aspergilli, we assessed the antifungal activity of the produced cocktail. The agar diffusion assay-a widely used technique in antimicrobial susceptibility testing-relies on water soluble and diffusible substances, which cannot be assumed for laetiporic acids. As an alternative dual strategy, we tested the bioactivity of polyenes (i) in situ during production in A. niger and A. nidulans (Fig. 4), and (ii) directly on A. nidulans protoplasts (Fig. 5). A. niger strains tPS01 (control) and tPS02 (lpaA-expressing) were cultivated in the absence or presence of $7.5-120 \mu \mathrm{g} \mathrm{ml}^{-1}$ doxycycline to induce gene expression dose-dependently [19]. While doxycycline hardly inhibited growth at $30-120 \mu \mathrm{g} \mathrm{ml}^{-1}$ in the tPS01 control, tPS02 was strongly impaired, and had produced less biomass (Fig. 4). Moreover, growth inhibition correlated with the dose-dependent intrinsic polyene concentration which reached its maximum at $7.5 \mu \mathrm{g}$ per mg biomass at $120 \mu \mathrm{g} \mathrm{ml}^{-1}$ doxycycline. In a complementary experiment, the lpaA-expressing strain A. nidulans tMG01 and its parental strain were cultivated in AMM with $200 \mathrm{mM}$ ethanol as carbon source, and variable amounts of glucose $(2.5-50 \mathrm{mM})$ were added prior to inoculation to dose-dependently repress gene expression. a

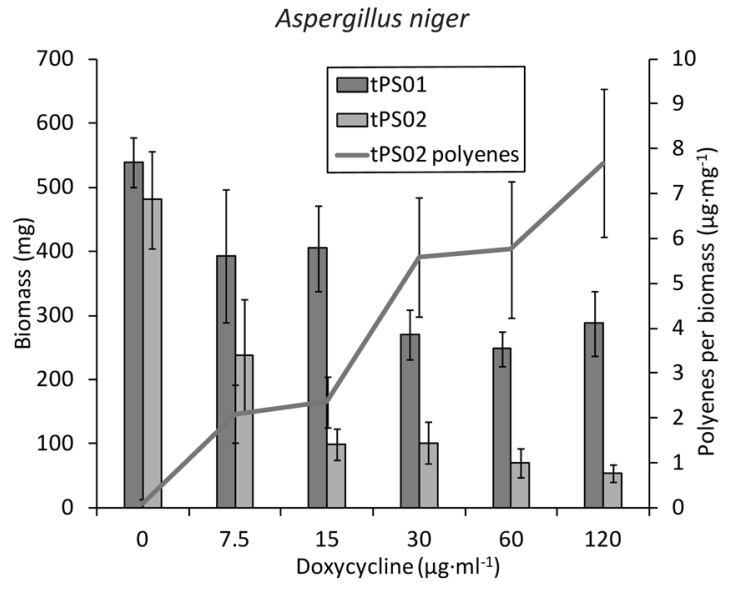

b

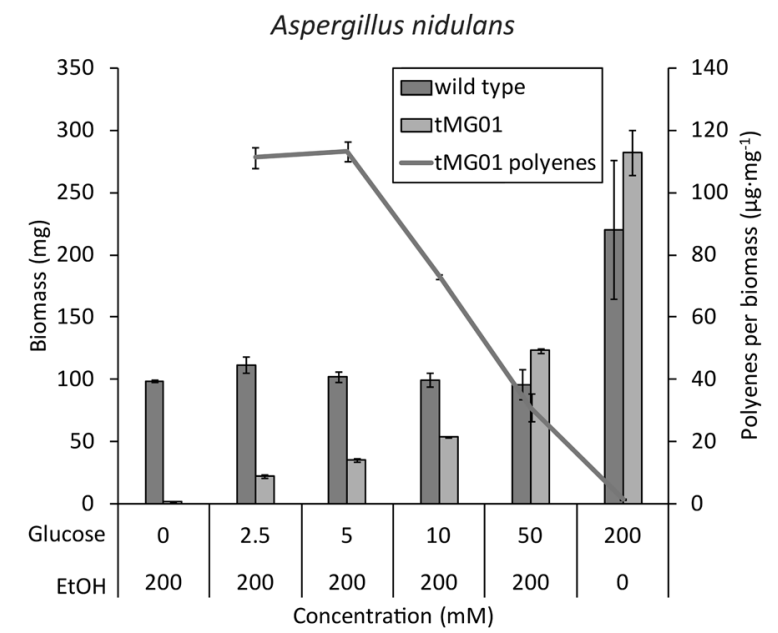

Fig. 4 Antifungal activity of laetiporic acids produced in situ by Aspergillus niger and Aspergillus nidulans. Fungal dry biomass (in $\mathrm{mg}$ ) was determined for A. niger tPS02 (lpaA-expressing) and tPS01 (vector control) (a) or A. nidulans tMG01 (lpaA-expressing) and FGSC A4 wildtype strain (b), respectively. Polyene production was induced by adding doxycycline $\left(7.5-120 \mu \mathrm{g} \mathrm{ml}^{-1}\right)$ in $A$. niger and repressed by D-glucose $(2.5-50 \mathrm{mM})$ in $A$. nidulans. Cultures without inducer, i.e., doxycycline for A. niger or ethanol in A. nidulans, served as negative controls. Intracellular polyene concentration is given in $\mu \mathrm{g}$ per mg dry fungal biomass. Polyene production is increased 15 -fold in A. nidulans, compared to A. niger, resulting in a more intense coloration and an antifungal effect (no growth under non-repressing conditions). Hence, polyene content could not be determined under this condition. Bars indicate the standard deviation $(n=3)$

Growth of the parental strain was not affected. In contrast, but similarly to what was observed for A. niger, growth inhibition was strongest when the highest intrinsic polyene concentration was reached $\left(110 \mu \mathrm{g} \mathrm{mg}^{-1}\right.$ polyenes at $2.5 \mathrm{mM}$ D-glucose). Moreover, without repressing D-glucose (that is, $200 \mathrm{mM}$ ethanol as sole carbon source), spores from tMG01 were arrested in the state of germination, indicating a strong antifungal activity. In a parallel experiment, the LpaA-produced cocktail of multi-chain length laetiporic acids was added to A. nidulans wild type protoplasts. Based on the number of colony-forming units, we observed a 


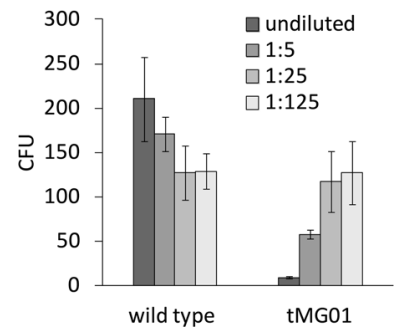

Fig. 5 Antifungal activity on Aspergillus nidulans protoplasts. Extracts of $A$. nidulans wild type (negative control) and tMG01 were prepurified, and added undiluted or diluted 1:5, 1:25, and 1:125, respectively, to a protoplast suspension. The undiluted tMG01 extract contained polyenes at a concentration of $4 \mathrm{mg} \mathrm{ml}^{-1}$. Bars indicate the standard deviation $(n=4)$; CFU: colony forming units

significantly reduced protoplast viability with undiluted and 1:5 diluted extract, compared to $A$. nidulans wild type extracts (Fig. 5).

\section{Discussion}

Conjugated double bonds are a widespread feature of biologically active natural products, among them the leukotrienes, carotenoids, and clinically used antimicrobially active polyenes, such as nystatin and amphotericin. In the context of basidiomycetes, polyenes are remarkable in that they occur erratically and in taxonomically unrelated groups, among them the Russulales [4] and the Polyporales $[5,6]$. Knowledge on the biosynthesis of basidiomycete highly reduced polyketide is scanty. To date, PPS1, the characterized polyene synthase of BY1, a stereaceous basidiomycete [4], is the only reported example. To exclude host-specific effects, we relied on two independent heterologous systems: in one system gene expression is mediated by increasing concentrations of an inductor (doxycycline), while in the second system, the ethanol-mediated induction was attenuable by increasing D-glucose concentrations as repressor. Yet, the polyene profiles were highly congruent, independent of the used strategy.

The combined results from PPS1 and the Laetiporus enzyme LpaA reveal common features between these two synthases from unrelated species. Remarkably, polyenes of variable chain length seem to be an intrinsic property of either synthase, yet more pronounced with LpaA, as chain lengths varied between $\mathrm{C}_{26}$ and $\mathrm{C}_{32}$, while PPS1 produces polyenes with $\mathrm{C}_{20}-\mathrm{C}_{22}$ main chains. Further, double bond shift (i.e., positioned within formal acetate units, rather than between them) is a shared intrinsic property of LpaA and PPS1. In the case of 2-dehydro-3-deoxylaetiporic acid A (Fig. 1), one double bond remains at the canonical $\alpha, \beta$-position, although this may be a secondary effect as well and the consequence of water elimination. Finally, either enzyme showed a preference for a particular chain length, in the case of LpaA primarily $\mathrm{C}_{28}$ and $\mathrm{C}_{30}$ main chains (i.e., laetiporic acids $B$ and $C$ ).

Remarkably, LpaA, i.e., a single enzyme, produces an entire set of compounds, which once again supports both the notion of a diversity-oriented secondary metabolism [20] and an emerging concept of multi-product PKSs. Described examples include, e.g., PKS1 of Colletotrichum lagenarium that produces tetra- to hexaketides [21] and the A. terreus polyketide synthase TerA, which makes tri- to pentaketides [22]. Building upon prior results by Weber et al., we here show that a single enzyme produces four chains, which provides the first layer of diversification and underscores that $\mathrm{LpaA}$ has been evolved for diversity, rather than specificity. The second layer to generate diversity is elimination of a formal water molecule from positions $\mathrm{C}-3$ and C-4. Elimination of water is a natural, previously described process $[5,6]$, which is confirmed by our results. A third dimension to generate diversity is the configuration of double bonds.

Knowledge about the ecological role of basidiomycete polyenes is incomplete, yet inhibition of insect larvae was shown by previous works $[1,2,4]$. Our results on both Aspergillus protoplasts and the transgenic Aspergilli add antifungal activity to the biological effects of basidiomycete polyenes. Given the lipophilic character and the length of Laetiporus polyenes, activity may be exerted through interference with membranes. However, the assay system included wall-less cells and a production in situ. Therefore, future research is warranted to determine, if intact cell walls protect mycelium from being inhibited. Still, our results confirm the Basidiomycota as prolific producers of antibiotic compounds [23]. Hallmark examples are the agriculturally used fungicides derived from strobilurine [24], or the clinically used derivatives of the antibacterial pleuromutilin [25]. The results presented here contribute to efforts, reflected by this special issue of the Journal of Antibiotics, to understand this aspect of basidiomycete biology more profoundly.

Acknowledgements We thank Andrea Perner (Hans-Knöll-Institute Jena) for recording high-resolution mass spectra. We thank Patricia Hübel and Erik Fischer (Friedrich-Schiller-University Jena) for additional compound purification. We thank Matthias Brock, University of Nottingham for providing A. niger ATNT16 1 pyrGx24 and plasmid pSMX2-URA. CL acknowledges a doctoral fellowship by the International Leibniz Research School (ILRS) for Microbial Interactions. DH is supported by the DFG Collaborative Research Center ChemBioSys 1127.

Funding Open access funding provided by Projekt DEAL.

\section{Compliance with ethical standards}

Conflict of interest The authors declare that they have no conflict of interest. 
Publisher's note Springer Nature remains neutral with regard to jurisdictional claims in published maps and institutional affiliations.

Open Access This article is licensed under a Creative Commons Attribution 4.0 International License, which permits use, sharing, adaptation, distribution and reproduction in any medium or format, as long as you give appropriate credit to the original author(s) and the source, provide a link to the Creative Commons license, and indicate if changes were made. The images or other third party material in this article are included in the article's Creative Commons license, unless indicated otherwise in a credit line to the material. If material is not included in the article's Creative Commons license and your intended use is not permitted by statutory regulation or exceeds the permitted use, you will need to obtain permission directly from the copyright holder. To view a copy of this license, visit http://creativecommons. org/licenses/by/4.0/.

\section{References}

1. Gill M. Polyolefinic 18-methyl-19-oxoicosenoic acid pigments from the fungus Piptoporus australiensis (Wakefield) Cunningham. J Chem Soc Perkin Trans. 1982;1:1449-53.

2. Gill M, Steglich W. Pigments of fungi (Macromycetes). In: Herz W, Grisebach H, Kirby GW, Tamm C. editors. Progress in the chemistry of organic natural products. Vienna, New York: Springer; 1987.

3. Schwenk D, Nett M, Dahse HM, Horn U, Blanchette RA, Hoffmeister D. Injury-induced biosynthesis of methyl-branched polyene pigments in a white-rotting basidiomycete. J Nat Prod. 2014;77:2658-63.

4. Brandt P, García-Altares M, Nett M, Hertweck C, Hoffmeister D. Induced chemical defense of a mushroom by a double-bondshifting polyene synthase. Angew Chem Int Ed. 2017;56:5937-41.

5. Weber RWS, Mucci A, Davoli P. Laetiporic acid, a new polyene pigment from the wood-rotting basidiomycete Laetiporus sulphureus (Polyporales, Fungi). Tetrahedron Lett. 2004;45:1075-8.

6. Davoli P, Mucci A, Schenetti L, Weber RW. Laetiporic acids, a family of non-carotenoid polyene pigments from fruit-bodies and liquid cultures of Laetiporus sulphureus (Polyporales, Fungi). Phytochemistry. 2005;66:817-23.

7. Geib E, Baldeweg F, Doerfer M, Nett M, Brock M. Crosschemistry leads to product diversity from atromentin synthetases in Aspergilli from section Nigri. Cell Chem Biol. 2019;26:223-34.

8. Pontecorvo G, Roper JA, Hemmons LM, Macdonald KD, Bufton AWJ. The genetics of Aspergillus nidulans. In: Demerec M. Advances in genetics. 5th ed. New York, N.Y.: Academic Press; 1953. p. 141-238.
9. Dörfer M, et al. Melleolides impact fungal translation via elongation factor 2. Org Biomol Chem. 2019;17:4906-16.

10. Nagy LG, et al. Comparative genomics of early-diverging mushroom-forming fungi provides insights into the origins of lignocellulose decay capabilities. Mol Biol Evol. 2016;33:959-70.

11. Kwan DH, Leadlay PF. Mutagenesis of a modular polyketide synthase enoylreductase domain reveals insights into catalysis and stereospecificity. ACS Chem Biol. 2010;5:829-38.

12. Maier T, Leibundgut M, Ban N. The crystal structure of a mammalian fatty acid synthase. Science. 2008;321:1315-22.

13. Kennedy J, et al. Modulation of polyketide synthase activity by accessory proteins during lovastatin biosynthesis. Science. 1999;284:1368-72.

14. Fujii I, Yoshida N, Shimomaki S, Oikawa H, Ebizuka Y. An iterative type I polyketide synthase PKSN catalyzes synthesis of the decaketide alternapyrone with regio-specific octa-methylation. Chem Biol. 2005;12:1301-09.

15. Neto FC, et al. Re-investigation of the fragmentation of protonated carotenoids by electrospray ionization and nanospray tandem mass spectrometry. Rapid Commun Mass Spectrom. 2016;30:1540-8.

16. Rivera SM, Christou P, Canela-Garayoa R. Identification of carotenoids using mass spectrometry. Mass Spectrom Rev. 2014;33:353-72.

17. Baker SE, et al. Two polyketide synthase-encoding genes are required for biosynthesis of the polyketide virulence factor, Ttoxin, by Cochliobolus heterostrophus. Mol Plant Microbe Int. 2006;19:139-49.

18. Kulmburg P, Mathieu M, Dowzer C, Kelly J, Felenbok B. Specific binding sites in the alcR and alcA promoters of the ethanol regulon for the CREA repressor mediating carbon catabolite repression in Aspergillus nidulans. Mol Microbiol. 1993;7:847-57.

19. Geib E, Brock M. ATNT: an enhanced system for expression of polycistronic secondary metabolite gene clusters in Aspergillus niger. Fungal Biol Biotechnol. 2017;4:13.

20. Firn RD, Jones CG. Natural products-a simple model to explain chemical diversity. Nat Prod Rep. 2003;20:382-91.

21. Watanabe A, Ebizuka Y. Unprecedented mechanism of chain length determination in fungal aromatic polyketide synthases. Chem Biol. 2004;11:1101-6.

22. Zaehle C, et al. Terrein biosynthesis in Aspergillus terreus and its impact on phytotoxicity. Chem Biol. 2014;21:719-31.

23. Schüffler A, Anke T. Fungal natural products in research and development. Nat Prod Rep. 2014;31:1425-48.

24. Sauter H, Steglich W, Anke T. Strobilurins: evolution of a new class of active substances. Angew Chem Int Ed. 1999;38:1328-49.

25. Novak R, Shlaes DM. The pleuromutilin antibiotics: a new class for human use. Curr Opin Investig Drugs. 2010;11:182-91. 